\title{
EFEITO DA UMIDADE E DO PERÍODO DE ARMAZENAMENTO HERMÉTICO NA CONTAMINAÇÃO NATURAL POR FUNGOS E A PRODUÇÃO DE MICOTOXINAS EM GRÃOS DE AVEIA
}

\author{
Effects of grain moisture and hermetic storage on fungi contamination \\ and mycotoxin production in oats
}

\author{
Galileu Rupollo ${ }^{1}$, Luiz Carlos Gutkoski ${ }^{2}$, Iure Rabassa Martins ${ }^{1}$, Moacir Cardoso Elias ${ }^{3}$
}

\begin{abstract}
RESUMO
Com o presente trabalho, objetivou-se avaliar a contaminação natural por fungos, produção de micotoxinas, composição em ácidos graxos e concentração de $\mathrm{CO}_{2}$ intergranular em grãos de aveia armazenados no sistema hermético por 12 meses. Grãos de aveia, da cultivar UPF 18 foram colhidos com $16 \%$ de umidade e realizado a secagem estacionária em protótipo silo-secador até as umidades de $15 \%, 12 \%$ e $9 \%$. Para os tratamentos com $18 \%$ e $21 \%$ de umidade foi realizada a reidratação pela colocação dos grãos em atmosfera saturada por cinco dias. Determinou-se a composição centesimal aproximada, composição em ácidos graxos, contaminação natural por fungos, presença de micotoxinas e concentração de $\mathrm{CO}_{2}$ intergranular. Os resultados foram analisados pela análise de variância, comparação de médias pelo teste de Tukey e análise de regressão. Não foi detectada a presença das micotoxinas aflatoxina $B_{1}, B_{2}, G_{1}$, $\mathrm{G}_{2}$, zearalenona e ocratoxina $\mathrm{A}$. A quantidade de $\mathrm{CO}_{2}$ na atmosfera intergranular apresentou comportamento linear e foi proporcional à umidade dos grãos e tempos de armazenamento. O aumento do tempo de armazenamento e da umidade dos grãos intensificou a redução de ácidos graxos insaturados, com predominância de ação sobre linoléico e linolênico.
\end{abstract}

Termos para indexação: Aveia, secagem, armazenamento, fungos, micotoxinas.

\begin{abstract}
This research aimed to evaluate the natural contamination by fungi, production of mycotoxins, fatty acids composition and the intergranular $\mathrm{CO}_{2}$ concentration in oat grains stored in a hermetic system for 12 months. The oat grains were harvested with $16 \%$ of moisture, being dried until $15 \%, 12 \%$ and $9 \%$ of moisture. Oat grains with $18 \%$ and $21 \%$ of moisture were obtained by a rehidrated, setting the grains in a saturated atmosphere for 5 days. The proximate percent composition, fatty acids profile, natural fungi contamination, mycotoxin production and the $\mathrm{CO}_{2}$ concentration were evaluated. The results were analyzed by analysis of variance and comparisons of means by Tukey's test and regression analysis of datas. The production of aflatoxins $\left(B_{1}, B_{2}, G_{1} e G_{2}\right)$, zearalenone and ochratoxin A were not detected. The amount of $\mathrm{CO}_{2}$ in the intergranular atmosphere in the hermetic storage showed a linear behavior and was directly related to the moisture and storage time. The increasing of the storage time and grains moisture caused the reduction of unsaturated fatty acids, mainly linoleic and linolenic acids.
\end{abstract}

Index terms: Oat, drying, storage, fungi, mycotoxin.

(Recebido para publicação em 10 de fevereiro de 2005 e aprovado em 1 de setembro de 2005)

\section{INTRODUÇÃO}

Nos últimos anos, tem aumentado o consumo de aveia e seus subprodutos, impulsionado principalmente pelo melhor conhecimento sobre suas propriedades nutricionais e pelos benefícios que este cereal propicia à saúde. Desse modo, informações sobre colheita, secagem e armazenamento são fundamentais na manutenção da qualidade do grão (GUTKOSKI, 2000).

Os principais fatores que favorecem o desenvolvimento de fungos durante o armazenamento de grãos são umidade, temperatura, período de armazenamento, nível inicial de contaminação, impurezas, insetos, concentração de $\mathrm{CO}_{2}$ intergranular, condições físicas e sanitárias dos grãos (LAZZARI, 1997). Em condições ambientais favoráveis, de umidade e de temperatura, os esporos dos fungos germinam, desenvolvendo hifas, que infestam grãos, rações e outros substratos (PRADO et al., 1991).

Os fungos potencialmente capazes de produzir metabólitos secundários tóxicos são denominados toxigênicos e podem contaminar os grãos no campo, antes mesmo da colheita ou durante o armazenamento, persistindo em alimentos e rações destinados ao consumo humano e de animais (CARVAJAL \& ARROYO, 1997). Os fungos toxigênicos pertencem basicamente aos gêneros Aspergillus, Penicillium e Fusarium, os quais são

\footnotetext{
${ }^{1}$ Engenheiro Agrônomo, Mestre em Ciência e Tecnologia Agroindustrial da UFPel.

2 Engenheiro Agrônomo, Doutor, Professor da Faculdade de Agronomia e Medicina Veterinária da UPF- Cx. P. 611 - 99001-970 - Passo Fundo, RS. Bolsista CNPq - gutkoski@upf.br.

${ }^{3}$ Engenheiro Agrônomo, Doutor, Professor do Departamento de Ciência e Tecnologia Agroindustrial da UFPel.
} 
responsáveis pela produção da maioria das micotoxinas até hoje conhecidas e estudadas. As espécies de Fusarium são patógenos de plantas, produzindo micotoxinas antes da colheita ou imediatamente após ela. Os gêneros Penicillium e Aspergillus são mais comumente encontrados como contaminantes de produtos durante a secagem e o armazenamento, sendo denominados de fungos de armazenamento (SWEENWEY \& DOBSON, 1998).

As aflatoxinas $B_{1}, B_{2}, G_{1}$ e $G_{2}$ estão presentes nos cereais e a proporção é dependente da espécie de Aspergillus presente. O Aspergillus flavus produz aflatoxinas $\mathrm{B}_{1}$ e $\mathrm{B}_{2}$, enquanto o Aspergillus parasiticus produz as aflatoxinas $B_{1}, B_{2}, G_{1}$ e $G_{2}$ (MOSS, 1991). A toxicidade das aflatoxinas decresce na ordem $\mathrm{B}_{1}>\mathrm{B}_{2}>\mathrm{G}_{1}>\mathrm{G}_{2} . \mathrm{A} \mathrm{G}_{1}$ possui a metade da toxicidade de $\mathrm{B}_{1}$ (SCUSSEL, 2002).

A Zearalenona é uma lactona do ácido fenólico resorcílico, cuja estrutura sugere que ela seja sintetizada pela via do acetato-polimalonato, resultando na condensação de unidades de acetato produzida por várias espécies de Fusarium. O Fusarium graminearum é o maior produtor, sendo que os fungos Fusarium crookwellense e Fusarium semitectum também são considerados produtores de Zearalenona (SWEENWEY \& DOBSON, 1998).

A Ocratoxina A é caracterizada como um composto formado por uma $b$-fenilalanina ligada a uma isocumarina produzida pelo fungo Penicillium verrucosum. O crescimento deste fungo pode ocorrer nas temperaturas entre 0 e $31^{\circ} \mathrm{C}$, sendo $20^{\circ} \mathrm{C}$ a temperatura ótima. $\mathrm{O}$ fungo Aspergillus ochraceus também produz Ocratoxina A e por ser característico de climas quentes cresce em temperaturas entre 8 e $37^{\circ} \mathrm{C}$, com um ótimo entre 24 e $37^{\circ} \mathrm{C}$ (SWEENEY \& DOBSON, 1998).

Rodriguez-Amaya \& Sabino (2002), em levantamento bibliográfico sobre trabalhos de micotoxinas realizados por pesquisadores brasileiros no período entre 1991 e 2000 encontraram 128 publicações. A ocorrência de aflatoxinas em grãos oleaginosos continua alarmante. A incidência de fumosinas em produtos derivados de milho também parece ser um problema sério. As contaminações com Zearalenona, Ocratoxinas e Tricotecenos foram baixas. Em aveia os autores não encontraram publicações no período estudado. Com este trabalho objetivou-se avaliar a contaminação natural por fungos, produção de micotoxinas, composição de ácidos graxos e concentração de $\mathrm{CO}_{2}$ intergranular em grãos de aveia armazenados no sistema hermético por 12 meses.

\section{MATERIAL E MÉTODOS}

Para realizar este trabalho foram utilizados grãos de aveia (Avena sativa L), cultivar UPF 18, produzidas em um hectare, no Campo Experimental da Palma, da Universidade Federal de Pelotas, localizado no município do Capão do Leão, RS, na safra 2001. A colheita dos grãos foi realizada com colhedora automotriz na umidade de $16 \%$, sendo eles pré-limpos, em máquina de ar e peneiras. Para serem obtidas umidades nas faixas de $9 \%, 12 \%, 15 \%, 18 \%$ e $21 \%$, parte dos grãos foi submetida à secagem estacionária e parte reidratada. A secagem estacionária foi realizada em camada delgada de 1,0 m de altura no silo-secador protótipo, modelo Vitória com fluxo de ar axial e em velocidade constante de $0,1 \mathrm{~m} . \mathrm{s}^{-1}$, até as umidades de $15 \%, 12 \%$ e $9 \%$. Para a reidratação os grãos foram mantidos em câmara fria a $4{ }^{\circ} \mathrm{C}$ por cinco dias, em atmosfera saturada. Os grãos foram armazenados por um período de 12 meses no sistema hermético, em latas de 20 litros com $6 \mathrm{~kg}$ de aveia. As latas foram tampadas com pressão e também colocada fita vedante, para garantir a hermeticidade. Cada tratamento foi composto por 15 latas e em cada coleta de amostra (tempos zero, 3, 6, 9, 12 meses de armazenamento) para a realização de análises, a aveia restante era descartada. As avaliações do tempo zero de armazenamento foram realizadas logo após a secagem ou reidratação, conforme o caso. As análises realizadas foram as seguintes:

Composição centesimal aproximada- determinada na aveia recém colhida (tempo zero de armazenamento). Os lipídios totais foram quantificados em aparelho Soxhlet, de acordo com o método $\mathrm{n}^{\circ} 30.20$ da AACC (1995). A umidade e as cinzas foram determinadas de acordo com os métodos $\mathrm{n}^{\circ}$ 44-15A e 08-12 da AACC (1995). A proteína bruta $(\mathrm{N} \times \mathrm{6}, 25)$ foi determinada pelo método kjeldahl, conforme procedimento $\mathrm{n}^{\circ} 46-12$ da AACC (1995) e os carboidratos obtidos por diferença. As análises foram realizadas em triplicata e os resultados expressos em porcentagem e na base úmida.

Composição em ácidos graxos- determinada no grão recém colhido (tempo zero) e após os tempos 2 e 12 meses de armazenamento no sistema hermético. O óleo de aveia foi extraído em aparelho Soxhlet, os ésteres metílicos obtidos de acordo com Maia \& Rodriguez-Amaya (1993). A composição de ácidos graxos foi determinada por cromatografia gasosa empregando-se o cromatógrafo Varian Star 3400 CX, com integração automática e emprego da coluna DB-Wax $30 \mathrm{~m}$ x $25 \mathrm{~mm}$ x 0,25 mm. A identificação dos ácidos graxos foi realizada com o uso do padrão Supelco FAME Mix C8-C24, nº 18918. 
Contaminação fúngica- determinada nos tempos 0 , $3,6,9$, e 12 meses de armazenamento hermético pelo uso do Blotter Test, segundo a metodologia proposta por Neergaard (1997) e adotada como método oficial para análise microbiológica de sementes pelo Ministério da Agricultura, em três repetições de 100 sementes por amostra. A leitura foi realizada com o auxílio de microscópio estereoscópio, complementada com microscópio ótico, quando necessário a identificação dos gêneros dos fungos e os resultados expressos em porcentagem de grãos infectados.

Micotoxinas- a determinação das aflatoxinas $\mathrm{B}_{1}, \mathrm{~B}_{2}$, $G_{1}, G_{2}$, ocratoxina A e zearalenona na aveia foi realizada após os tempos de 2 e 12 meses de armazenamento por cromatografia em camada delgada, empregando-se cromafolhas de alumínio de sílica gel 60G, marca Merck (Darmstadt, Alemanha), de acordo com a metodologia proposta por Soares \& Rodriguez-Amaya (1989). Os padrões de micotoxinas utilizados foram da marca Sigma (St. Louis, MO, EUA), mantidos sob temperatura de congelamento, devidamente protegido da luz e vedados até o momento do preparo das soluções. As soluções padrões foram preparadas e padronizadas em espectrofotômetro, segundo a AOAC (1997), método $\mathrm{n}^{\circ}$ 917.22. Grãos de aveia com casca foram moídos e amostras de $50 \mathrm{~g}$ homogeneizadas em blender com metanol e solução de $\mathrm{KCl} 4 \%$ para extração das micotoxinas. Os resíduos obtidos na purificação foram homogeneizados e aplicados nas cromoplacas. Os padrões também foram aplicados como forma de comparação. Foi empregado os solventes tolueno, acetato de etila e ácido fórmico (60:40:0,5) para a eluição das micotoxinas. A análise visual foi realizada por observação da placa sob luz UV a $366 \mathrm{hm}$ e $254 \mathrm{hm}$ em cromatovisor, verificando a presença ou ausência de fluorescência das manchas das amostras analisadas em comparação com a fluorescência dos padrões.

Concentração de $\mathrm{CO}_{2}$ intergranular- determinada após os tempos 2 e 12 meses de armazenamento por cromatografia em fase gasosa, utilizando o cromatrógrafo Shimadzu ${ }^{\hat{a}} \mathrm{CR} 950$, equipado com coluna de aço inoxidável $1 / 18$ " e detector por condutividade térmica, realizado de acordo com Neves et al. (2003). Foi utilizado como padrão, solução de $\mathrm{CO}_{2}$ a $5 \%$. Amostras de $1 \mathrm{~mL}$ foram retiradas, com seringa, da atmosfera intergranular das latas, onde estavam armazenados hermeticamente e injetadas no cromatógrafo. A quantificação foi realizada correlacionando-se a média das alturas dos picos relativos de cada amostra com a média das alturas dos picos obtidos da solução padrão. Os resultados da produção de $\mathrm{CO}_{2}$ foram expressos em porcentagem.
Delineamento experimental e análise estatísticao experimento foi conduzido em delineamento inteiramente casualizado em arranjo fatorial $5 \times 5$, ou seja, cinco umidades de armazenamento $(9 \%, 12 \%, 15 \%, 18 \%, 21 \%)$ e cinco tempos de armazenamento (zero, 3, 6, 9, 12 meses), com três repetições. Os resultados foram analisados pelo emprego da análise de variância (Anova) e nos modelos significativos pelo teste $\mathrm{F}$, realizada a comparação múltipla de médias pelo emprego do teste de Tukey, a 5\% de probabilidade. O processamento de dados e a análise estatística foram realizados com o uso do programa estatístico SASâ (SAS INSTITUTE, 1985). As análises e os gráficos das equações de regressão foram elaborados com o auxílio do programa estatístico Microsoft Excel 2000â, no modo estatístico.

\section{RESULTADOS E DISCUSSÃO}

A composição da aveia com casca (tempo zero de armazenamento) foi 14,92\% de proteínas, 6,82\% de lipídios, $2,23 \%$ de cinzas, $13,52 \%$ de umidade e $62,51 \%$ de carboidratos. O teor de proteínas foi similar ao encontrado por Pedó \& Sgarbieri (1997) ao caracterizar quatro cultivares de aveia. A proteína bruta em grãos de aveia varia consideravelmente entre cultivares, bem como na mesma cultivar quando exposta a diferentes locais de cultivo. Grãos de aveia de 25 genótipos cultivados em diferentes ambientes no sul do Brasil apresentaram teores de proteínas entre $12,7 \%$ e 16,9\% (MILACH et al., 2000).

O teor de lipídios da aveia em estudo, 6,82\%, está abaixo dos resultados obtidos por Pedó \& Sgarbieri (1997), que obtiveram valores entre 7,18\% e 7,50\%, provavelmente por ter sido determinada a composição centesimal em grãos de aveia com casca. Gutkoski et al. (1997), em estudo de caracterização química da cultivar UPF 16, verificaram valores para os lipídios de 8,9\% na fração de granulometria superior a $532 \mathrm{~mm}, 8,0 \%$ na cariopse e $7,2 \%$ na fração de granulometria inferior a $532 \mathrm{~mm}$. O teor de cinzas encontrado ficou acima dos 2,0\% verificados por Pedó \& Sgarbieri (1997) pelo fato da aveia utilizada no presente trabalho ter sido analisada com casca.

Observou-se um aumento no conteúdo dos ácidos graxos saturados totais com o tempo de armazenamento, exceto para os tratamentos nas umidades de $9 \%$ e $12 \%$, em que ocorreu diminuição (Tabela 1). Em relação aos ácidos graxos insaturados, verificou-se que a concentração do ácido linolênico reduziu em todos os tratamentos com o aumento do tempo de armazenamento. Nos grãos de aveia armazenados nas umidades de $18 \%$ e $21 \%$, a redução do ácido linolênico após o período de 12 meses foi $66,1 \%$ e 
$61,7 \%$, respectivamente, em comparação com o de 2 meses de armazenamento. Também a concentração do ácido linoléico apresentou redução, sendo mais intenso nos tratamentos de grãos de aveia armazenados no sistema hermético com maiores teores de umidade.

A composição de lipídios na aveia é favorecida pelo alto teor de ácidos graxos insaturados, dentre eles o linoléico que é considerado essencial para a nutrição humana, sendo também o mais abundante. Neste trabalho, o teor de ácido linoléico encontrado no óleo de aveia recém colhida foi de $37,3 \%$. Por outro lado, essa composição contribui para a frágil estabilidade dos produtos de aveia e a formação de compostos indesejáveis (ZADERNOWSKI et al., 1999). Segundo Shahidi (1995), a determinação de voláteis individuais ou totais de compostos carbonílicos formados da degradação dos hidroperóxidos é uma alternativa para monitorar a extensão da rancidez oxidativa. A degradação e/ou aumento dos ácidos graxos presentes no óleo de aveia após 12 meses de armazenamento em comparação com a matéria-prima recém colhida no presente trabalho foi monitorado pela determinação da composição em ácidos graxos.

Molteberg et al. (1995) também não verificaram a redução no conteúdo de ácidos graxos insaturados de aveia armazenada por 15,5 meses a umidades de até 14,5\%. Nas amostras que sofreram processamento, o ácido linolênico apresentou redução, o que está relacionado com o aumento do conteúdo de produtos de oxidação. A diminuição do ácido linolênico no armazenamento e processamento ocorreu em função de sua degradação a compostos menores. Molteberg et al. (1995) verificaram que mesmo na aveia não processada e armazenada na umidade relativa de $80 \%$ a formação de hexanal foi 2 vezes maior quando comparado com a aveia armazenada a $30 \%$ de umidade relativa.

Em relação a contaminação natural por fungos observou-se que, a interação foi significativa ( $\mathrm{p} £ 0,05)$ entre umidade e período de armazenamento sobre a dinâmica populacional dos fungos dos gêneros Aspergillus, Penicillium e Fusarium em grãos de aveia armazenados no sistema hermético (Figuras 1, 2 e 3). Nos tratamentos com umidades inferiores a $15 \%$ verificou-se a predominância de outros fungos, cuja incidência decresceu na ordem dos gêneros Colletotrichum, Chaetomium, Phoma, Bipolaris, Alternaria e Neurospora. Umidades mais elevadas favoreceram a incidência dos fungos dos gêneros Aspergillus, Penicillium, Fusarium. A incidência fúngica no início do armazenamento refere-se basicamente à contaminação vinda da lavoura, ou seja, fungos de campo, pois esses fungos desenvolvem-se melhor em umidades relativas mais elevadas (TANAKA et al., 2001).

TABELA 1 - Composição em ácidos graxos dos lipídios de aveia da cultivar UPF 18 recém colhida (matéria-prima) e dos grãos armazenados no sistema hermético a 9\%, 12\%, 15\%, 18\% e 21\% de umidade por 2 e 12 meses $^{1}$.

\begin{tabular}{|c|c|c|c|c|c|c|c|c|c|c|c|}
\hline \multirow{3}{*}{ Ácidos graxos } & \multicolumn{11}{|c|}{ Período de armazenamento (meses) } \\
\hline & \multirow{2}{*}{$\begin{array}{c}\text { o } \\
\begin{array}{c}\text { Matéria } \\
\text { prima }\end{array}\end{array}$} & \multicolumn{4}{|c|}{2} & \multicolumn{6}{|c|}{12} \\
\hline & & $\begin{array}{c}9 \% \\
\text { b.u. }\end{array}$ & $\begin{array}{l}12 \% \\
\text { b.u. }\end{array}$ & $\begin{array}{l}15 \% \\
\text { b.u. }\end{array}$ & $\begin{array}{l}18 \% \\
\text { b.u. }\end{array}$ & $\begin{array}{l}21 \% \\
\text { b.u. }\end{array}$ & $\begin{array}{l}9 \% \\
\text { b.u. }\end{array}$ & $\begin{array}{l}12 \% \\
\text { b.u. }\end{array}$ & $\begin{array}{l}15 \% \\
\text { b.u. }\end{array}$ & $\begin{array}{l}18 \% \\
\text { b.u. }\end{array}$ & $\begin{array}{l}21 \% \\
\text { b.u. }\end{array}$ \\
\hline Mirístico C 14:0 & 0,00 & 0,12 & 0,16 & 0,15 & 0,09 & 0,21 & 0,13 & 0,18 & 0,22 & 0,12 & 0,25 \\
\hline Palmítico C 16:0 & 13,3 & 15,03 & 16,01 & 14,64 & 15,6 & 16,1 & 14,5 & 14,67 & 16,65 & 17,56 & 17,56 \\
\hline Esteárico C 18:0 & 1,70 & 1,65 & 1,72 & 1,61 & 1,68 & 1,92 & 1,75 & 1,67 & 2,35 & 2,2 & 2,2 \\
\hline Araquídico C 20:0 & 1,30 & 0,95 & 0,83 & 1,07 & 0,9 & 0,8 & 1,19 & 1,16 & 1,16 & 1,3 & 1,06 \\
\hline Total saturados & 16,4 & 17,75 & 18,72 & 17,47 & 18,27 & 19,03 & 17,64 & 17,68 & 20,38 & 21,18 & 21,07 \\
\hline Oléico C18:1 & 43,8 & 41,55 & 41,03 & 42,04 & 42,32 & 41,06 & 42,91 & 43,15 & 40,53 & 45,74 & 43,93 \\
\hline Linoléico C 18:2 & 37,5 & 39,21 & 38,87 & 39,16 & 38,15 & 38,49 & 38,13 & 38,06 & 38,04 & 32,3 & 34,12 \\
\hline Linolênico C 18:3 & 2,3 & 1,49 & 1,38 & 1,33 & 1,26 & 1,42 & 1,25 & 1,11 & 1,05 & 0,78 & 0,88 \\
\hline Total insaturados & 83,6 & 82,25 & 81,28 & 82,53 & 81,73 & 80,97 & 82,36 & 82,32 & 79,62 & 78,82 & 78,93 \\
\hline
\end{tabular}

${ }^{1}$ Resultados são médias de duas determinações;

${ }^{2}$ b.u. - percentual de umidade, expresso em base úmida. 

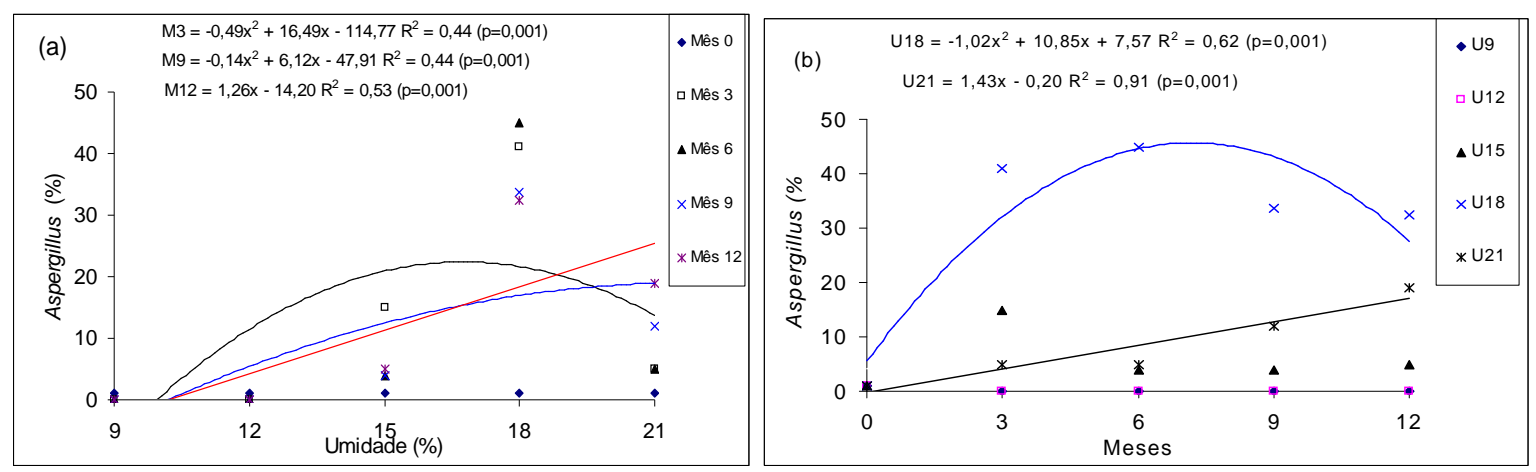

FIGURA 1 - Contaminação natural por fungos (em \% de grãos infectados) do gênero Aspergillus em aveia armazenada no sistema hermético a $9 \%, 12 \%, 15 \%, 18 \%$ e $21 \%$ de umidade (a) e por $0,3,6,9$ e 12 meses (b).
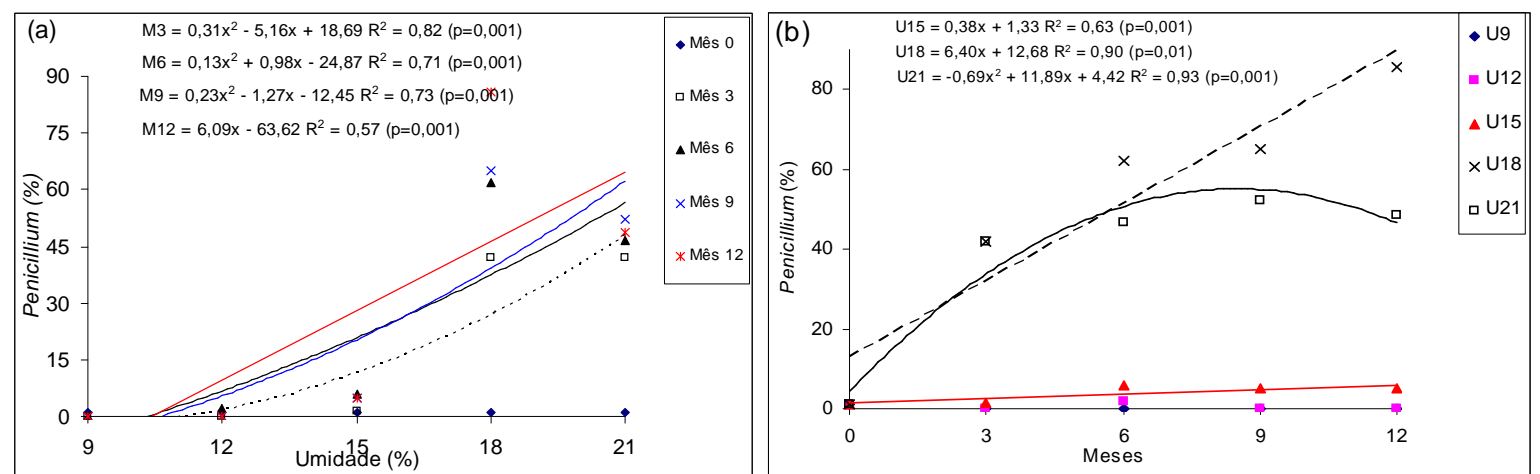

FIGURA 2 - Contaminação natural por fungos (em \% de grãos infectados) do gênero Penicillium em aveia armazenada no sistema hermético a $9 \%, 12 \%, 15 \%, 18 \%$ e $21 \%$ de umidade (a) e por $0,3,6,9$ e 12 meses (b).
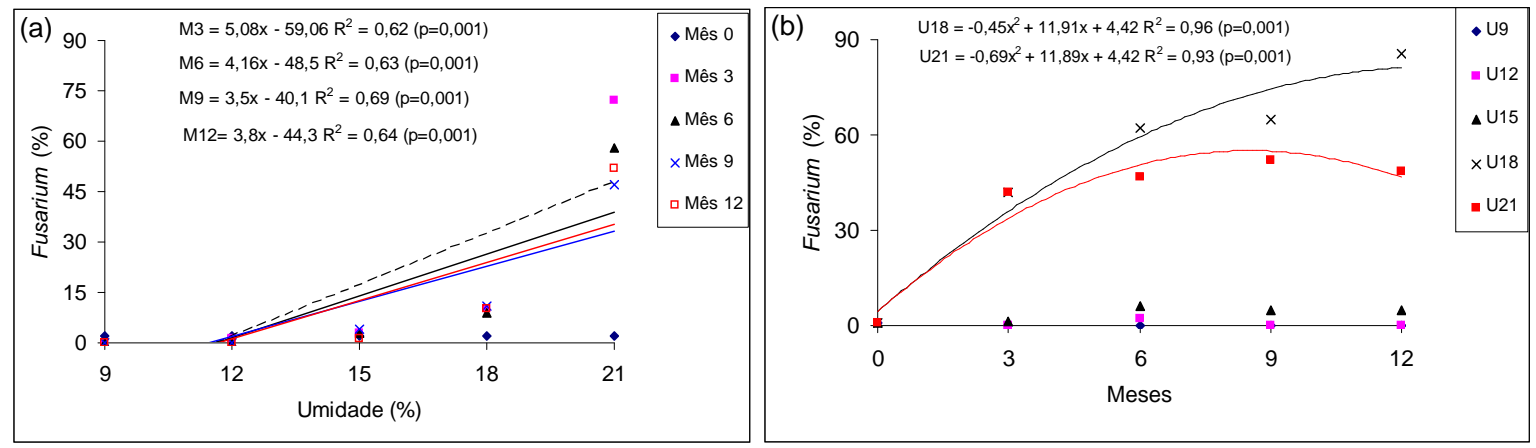

FIGURA 3 - Contaminação natural por fungos (em \% de grãos infectados) do gênero Fusarium em aveia armazenada no sistema hermético a $9 \%, 12 \%, 15 \%, 18 \%$ e $21 \%$ de umidade (a) e por $0,3,6,9$ e 12 meses (b).

Ciênc. agrotec., Lavras, v. 30, n. 1, p. 118-125, jan./fev., 2006 
Nos grãos de aveia armazenados a $9 \%$ e a $12 \%$ de umidade as equações de regressão não foram significativas, sendo verificado uma contaminação dos gêneros Aspergillus, Penicillium, Fusarium relativamente baixa durante o período de armazenamento estudado. Já nas umidades de $15 \%, 18 \%$ e $21 \%$ de armazenamento as equações de regressão foram significativas (p£0,05), exceto para Fusarium (Figura 3). As maiores incidências dos gêneros Aspergillus e Penicillium ocorreram na umidade de $18 \%$, seguindo-se de $21 \%$ e $15 \%$. Para o gênero Fusarium, a maior incidência foi verificada em grãos armazenados com $21 \%$ de umidade.

Em relação ao período de armazenamento, observouse que os gêneros Aspergillus, Penicillium e Fusarium aumentaram. Os fungos do gênero Aspergillus apresentaram maiores incidências aos 3 meses e 6 meses de armazenamento (Figura 1). A diminuição da contaminação fúngica a partir do sexto mês armazenamento pode ter sido provocada pela perda da viabilidade dos esporos, que são facilmente sujeitos à dessecação (VALARINI et al., 1990).

Segundo Frisvad (1995), quando realizado o armazenamento em umidade elevada e temperatura ambiente ocorre um aumento no metabolismo dos grãos, favorecendo o crescimento microbiano. A contaminação por fungos é natural e permanente e em condições ambientais, os grãos que apresentam umidade elevada na colheita favorecem a predominância dos fungos de campo, neste trabalho denominados de outros fungos. Sweenwey $\&$ Dobson (1998) afirmam que durante um longo período de armazenamento, fungos xerófilos dos gêneros Aspergillus e Penicillium, denominados fungos de armazenamento, progressivamente substituem os fungos de campo. No presente trabalho verificou-se que a maior incidência dos fungos dos gêneros Aspergillus, Penicillium e Fusarium ocorreu nos grãos de aveia armazenados nas umidades $18 \%$ e $21 \%$.

Além da determinação da contaminação fúngica foi investigada a presença de aflatoxinas $B_{1}, B_{2}, G_{1}, G_{2}$, zearalenona e ocratoxina $A$, não sendo verificado nas condições do método analítico utilizado na presença de micotoxinas nos tratamentos estudados. Scudamore et al. (1999), examinando grãos de aveia, trigo e cevada detectaram em $21 \%$ das amostras na presença da micotoxina Ocratoxina $\mathrm{A}$, com maior frequiência em cevada do que em trigo e aveia. Os autores também observaram um aumento na frequiência de amostras contaminadas com o tempo de armazenamento. Embora com baixa incidência de micotoxinas, os resultados diferem do presente trabalho em que não foi detectado a presença das micotoxinas aflatoxinas $B_{1} B_{2} G_{1} G_{2}$ zearalenona e ocratoxina $A$ em grãos de aveia armazenados no sistema hermético pelo período de 12 meses.

A quantidade do ácido graxo linolênico, a atividade da enzima lipoxigenase, a predominância de fungos saprófitas, os antioxidantes presentes naturalmente, a concentração de $\mathrm{CO}_{2}$ da atmosfera intergranular e a capacidade de complexação dos minerais pelo ácido fítico (DILKIN et al., 2000; PETERSON, 2001; ZERINGUE et al., 1996), também podem ser apontados como fatores que interferiram na não ocorrência de micotoxinas em grãos de aveia armazenados pelos sistemas convencional e hermético a $8 \%, 11 \%$ e $14 \%$ de umidade por 12 meses, pelo menos em quantidades não detectáveis na sensibilidade da metodologia analítica utilizada.

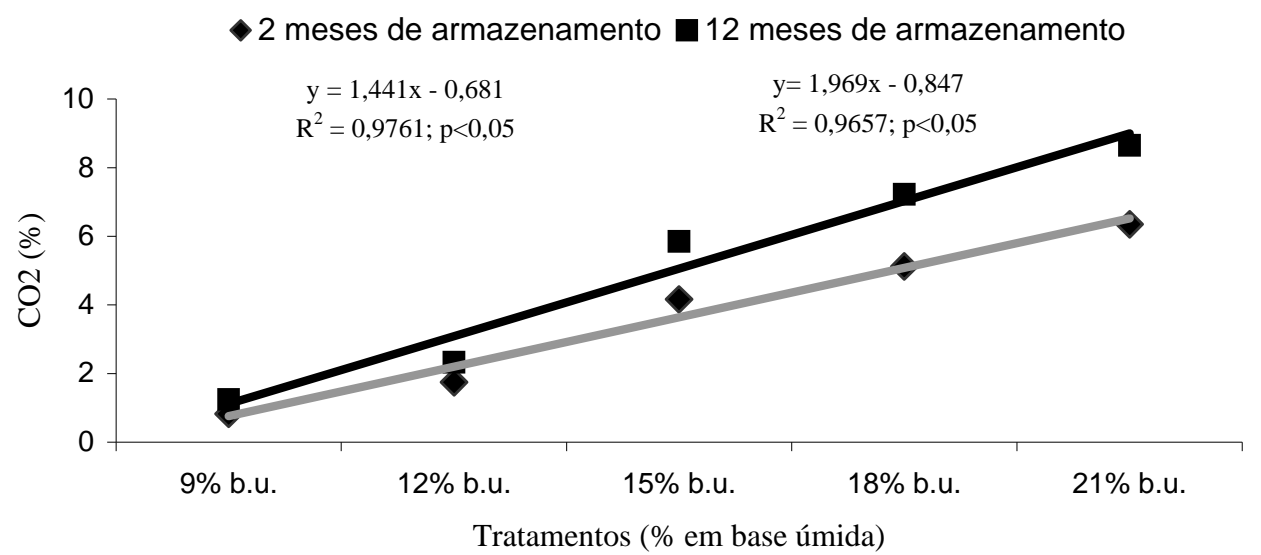

FIGURA 4 - Concentração de $\mathrm{CO}_{2}$ intergranular em aveia, cultivar UPF 18, armazenada no sistema hermético em cinco umidades por 2 e 12 meses. 
A produção de $\mathrm{CO}_{2}$ pelo grão foi diretamente proporcional ao seu grau de umidade e ao tempo de armazenamento, o que pode ser comprovado pelas equações de regressão linear obtidas após 2 e 12 meses de armazenamento, significativas a 5\% de probabilidade de erro (p£0,05), cujos coeficientes de determinação foram 0,9761 e 0,9657, respectivamente (Figura 4). O aumento linear do $\mathrm{CO}_{2}$ com a elevação da umidade pode explicar o efeito conservativo do $\mathrm{CO}_{2}$ na massa de grãos, diferentemente do que ocorre no armazenamento convencional.

No armazenamento pelo sistema hermético, $\mathrm{o} \mathrm{CO}_{2}$ produzido estabiliza o processo de degradação da massa de grãos e cessa a respiração pela redução da relação oxigênio/gás carbônico, diminuindo a produção de água e calor, os processos respiratórios e o ataque por microrganismos. De fato, a maior causa da produção de $\mathrm{CO}_{2}$ e perda de matéria seca em cereais armazenados é devida à incidência de microrganismos (FERNANDEZ et al., 1985; FLEURAT-LESSARD, 2002; MILLER, 1995; MUIR et al., 1985).

\section{CONCLUSÕES}

Os resultados experimentais obtidos neste trabalho permitem concluir que não foram detectadas as micotoxinas aflatoxinas $B_{1}, B_{2}, G_{1}$ e $G_{2}$, Zearalenona e Ocratoxina $\mathrm{A}$ em grãos de aveia armazenados no sistema hermético por 12 meses. A quantidade de $\mathrm{CO}_{2}$ intergranular no armazenamento hermético apresentou comportamento linear e foi diretamente proporcional à umidade e ao tempo de armazenamento. O teor de umidade dos grãos influenciou a incidência fúngica durante o armazenamento hermético, predominando os gêneros Aspergillus e Penicillium a 18\% e do Fusarium a $21 \%$. O aumento do período de armazenamento e de umidade dos grãos em valores superiores a $12 \%$ intensificou a redução dos conteúdos de ácidos graxos insaturados, com predominância de ação sobre o linoléico e linolênico.

\section{AGRADECIMENTOS}

Os autores agradecem ao Conselho Nacional de Desenvolvimento Científico e Tecnológico $\mathrm{MCT} / \mathrm{CNPq}$, pelo auxílio financeiro ao projeto.

\section{REFERÊNCIAS BIBLIOGRÁFICAS}

AMERICAN ASSOCIATION OF CEREAL CHEMISTS. Approved methods. 9. ed. Saint Paul, 1995.
ASSOCIATION OF OFFICIALANALYTICAL CHEMISTS. Official methods of analysis. 16. ed. Arlington: Washington, 1997. $2 \mathrm{v}$.

CARVAJAL, M.; ARROYO, G. Management of aflatoxin contaminated maize in Tarmaulipas, México. Journal of Agricultural and Food Chemistry, Washington, v. 45, n. 4, p. 1301-1305, 1997.

DILKIN, P.; MALLMANN, C. A.; SANTURIO, J. M.; HICKMANN, J. L. Classificação macroscópica, identificação da microbiota fúngica e produção de aflatoxinas em híbrido de milho. Ciência Rural, Santa Maria, v. 30, n. 1, p. 137-141, 2000.

FERNANDEZ, A.; STROSHINE, R.; TUITE, J. Mould growth and carbon dioxide production during storage of high moisture corn. Cereal Chemistry, Saint Paul, v. 62, p. 137-143, 1985.

FLEURAT-LESSARD, F. Qualitative reasoning and integrated management of the quality of stored grain: a promising new approach. Journal of Stored Products Research, Amsterdam, v. 38, p. 191-218, 2002.

FRISVAD, J. C. Mycotoxins and mycotoxigenic fungi in storage. In: JAYAS, D. S.; WHITE, N. D. G.; MUIR, W. E. (Eds.). Stored-grain ecosystems. New York: M. Dekker, 1995. p. 251-288.

GUTKOSKI, L. C. Composição química. In: GUTKOSKI, L. C.; PEDO, I. Aveia: composição química, valor nutricional e processamento. São Paulo: Varela, 2000. $96 \mathrm{p}$.

GUTKOSKI, L. C.; EL-DASH, A. A.; PEDÓ, I. Caracterização química e nutricional de frações de moagem de aveia. Arquivos de Biologia e Tecnologia, Curitiba, v. 40, n. 1, p. 121-134, 1997.

LAZZARI, F. A. Umidade, fungos e micotoxinas na qualidade de sementes, grãos e rações. 2. ed. Curitiba: [s.n.], 1997. $148 \mathrm{p}$.

MAIA, E. L.; RODRIGUEZ-AMAYA, D. B. Avaliação de um método simples e econômico para a metilação de ácidos graxos com lipídios de diversas espécies de peixes. Revista do Instituto Adolfo Lutz, São Paulo, v. 53, n. 1/2, p. 23-35, 1993. 
MILACH, S. C. K.; TISIAN, L. M.; WEILER, R.; FEDERIZZI, L. C.; TEIXEIRA, M. C.; LIMBERGER, E. Conteúdo de proteína em genótipos de aveia cultivados em diferentes ambientes do sul do Brasil. In: REUNIÃO DA COMISSÃO BRASILEIRA DE PESQUISA DEAVEIA, 20., 2000, Pelotas. Anais... Pelotas: UFPel, 2000. p. 141-143.

MILLER, J. D. Fungi and mycotoxins in grain: implications for stored product research. Journal Stored Products Research, Amsterdam, v. 31, n. 1, p. 1-16, 1995.

MOLTEBERG, G. L.; VOGT, G.; NILSSON, A.; FROLICH, W. Effects of storage and heat processing on the content and composition of free fatty acids in oats. Cereal Chemistry, Saint Paul, v. 72, n. 1, p. 88-93, 1995.

MOSS, M. O. Economic importance of mycotoxins-recent incidence. International Biodeteroration, Birmingham, v. 27, p. 195-205, 1991.

MUIR, W. E.; WATERER, D.; SINHA, R. N. Carbon dioxide as an early indicator of stored cereals and oilseed spoilage. Transactions of the ASAE, Saint Joseph, v. 28, p. 16731675, 1985.

NEERGAARD, P. Incubation tests. In: Seed pathology.London: Macmillan, 1977. p. 739-743.

NEVES, L. C.; CORRENT, A.; MARINI, L. J.; LUCCHETTA, L.; ZANUZO, M. R.; GONÇALVES, E. D.; ZANATTA, J.; CANTILHANO, F. R.; ROMBALDI, C. V. Atmosfera modificada e L-metilciclopropeno na conservação póscolheita de Kiwis cultivar Bruno. Revista Brasileira de Fruticultura, Jaboticabal, v. 25, n. 3, p. 390-393, 2003.

PEDÓ, I.; SGARBIERI, V. C. Caracterização química de cultivares de aveia (Avena sativa $\mathrm{L}$ ). Ciência e Tecnologia de Alimentos, Campinas, v. 17, n. 2, p. 78-83, 1997.

PETERSON, D. M. Oat antioxidants. Journal of Cereal Science, Saint Paul, n. 33, p. 115-129, 2001.

PRADO, G.; MATTOS, S. V. M.; PEREIRA, E. C. Efeito da umidade relativa na contaminação microbiana e produção de aflatoxinas em amendoim em grão. Ciência e Tecnologia de Alimentos, Campinas, v. 11, n. 2, p. 264-273, 1991.

RODRIGUEZ-AMAYA, D. B.; SABINO, M. Mycotoxin research in Brazil: the last decade in review. Brazilian Journal of Microbiology, Campinas, v. 33, p. 1-11, 2002.
SAS INSTITUTE. User's guide: statistics. 5. ed. Cary, 1985. $956 \mathrm{p}$.

SCUDAMORE, K. A.; PATEL, S.; BREEZE, V. Surveillance of stored grain from the 1997 harvest in the United Kingdom for ochratoxin A. Food Additives and Contaminants, New York, v. 16, n. 7, p. 281-290, 1999.

SCUSSEL, V. M. Fungos em grãos armazenados. In: LORINI, I.; MIIKE, L. H.; SCUSSEL, V. M. Armazenagem de grãos. Campinas: IBG, 2002. p. 675-804.

SHAHIDI, F. Stability of fats and oils. In: CONGRESSO E EXPOSIÇÃO LATINO AMERICANO SOBRE PROCESSAMENTO DE ÓLEOS E GORDURAS, 1995, Campinas. Anais... Campinas: [s.n.], 1995. p. 47-54.

SOARES, L. M. V.; RODRIGUEZ-AMAYA, D. B. Survey of aflatoxins, ochratoxin A zearalenone and stergmatocystin in some Brazilian foods by using multitoxin thin-layer chromatographic method. Journal of the Association of Official Analytical Chemist, Arlington, v. 72, p. 22-26, 1989.

SWEENWEY, M. J.; DOBSON, A. D. W. Mycotoxin production by Aspergillus, Fusarium and Penicillium species. International Journal of Food Microbiology, Amsterdam, v. 43, p. 141-158, 1998.

TANAKA, M. A. S.; MAEDA, J. A.; ALMEIDA, I. H.; PLAZAS, Z. Microflora fúngica de sementes de milho em ambientes de armazenamento. Scientia Agrícola, Piracicaba, v. 58, n. 3, p. 501-508, 2001.

VALARINI, P. J.; VECHIATO, M. H.; LASCA, C. C. Sobrevivência de fungos associados a sementes de arroz (Oryza sativa) em duas condições de armazenamento. Fitopatologia Brasileira, Brasília, v. 15, n. 3, p. 173-176, 1990.

ZADERNOWSKI, R.; POLAKOWSKA, H. N.; RASHED, A. A. The influence of heat treatment on the activity of lipo and hydrophilic components of oat grain. Journal of Food Processing and Preservation, [S.1.], v. 23, p. 177-191, 1999.

ZERINGUE, H. J.; BROWN, R. L.; NEUCERE, J. N. Relationship between $\mathrm{C}_{6}-\mathrm{C}_{12}$ alkanal and alkenal volatile contents and resistance of maize genotypes to Aspergillus flavus and aflatoxin production. Journal of Agricultural Food Chemistry, Washington, v. 44, p. 403-407, 1996. 